\title{
Differential Expression of Genes between Storage Roots of Sweetpotato Cultivars Jewel and White Jewel
}

\author{
Cecilia E. McGregor and Don R. LaBonte ${ }^{1}$ \\ Department of Horticulture, Louisiana State University AgCenter, Baton Rouge, LA 70803
}

\begin{abstract}
AdDitional Index words. $\beta$-carotene, gene expression, Ipomoea batatas, mutant, sugars
Aвstract. 'White Jewel' is a yellow-and-orange fleshed spontaneous mutant of the orange-flesh sweetpotato [Ipomoea batatas (L.) Lam.] cultivar Jewel. Mutations in storage root flesh color, and other traits are common in sweetpotato. The orange flesh color of sweetpotato is due to $\beta$-carotene stored in chromoplasts of root cells. $\beta$-carotene is important because of its role in human health. In an effort to elucidate biosynthesis and storage of $\beta$-carotene in sweetpotato roots, microarray analysis was used to investigate genes differentially expressed between 'White Jewel' and 'Jewel' storage roots. $\beta$-carotene content calculated from a* color values of 'Jewel' and 'White Jewel' were $20.66 \mathrm{mg} / 100 \mathrm{~g}$ fresh weight $(\mathrm{FW})$ and $1.68 \mathrm{mg} / 100 \mathrm{~g} \mathrm{FW}$, respectively. Isopentenyl diphosphate isomerase (IPI) was down-regulated in 'White Jewel', but farnesyl-diphosphate synthase (FPPS), geranylgeranyl diphosphate synthase (GGPS), and lycopene $\beta$-cyclase (LCY-b) were not differentially expressed. Several genes associated with chloroplasts were differentially expressed, indicating probable differences in chromoplast development of 'White Jewel' and 'Jewel'. Sucrose Synthase was down-regulated in 'White Jewel' and fructose and glucose levels in 'White Jewel' were lower than in 'Jewel' while sucrose levels were higher in 'White Jewel'. No differences were observed between dry weight or alcohol insoluble solids of the two cultivars. This study represents the first effort to elucidate $\beta$-carotene synthesis and storage in sweetpotato through large-scale gene expression analysis.
\end{abstract}

Sweetpotato is a hexaploid $(2 \mathrm{n}=6 \mathrm{x}=90)$ member of the Convolvulaceae family with extensive variation within the species. Commercial sweetpotato varieties are asexually propagated through adventitious sprouts from fleshy roots. This vegetative propagation should theoretically ensure that clonal varieties are genotypically uniform (Villordon and LaBonte, 1995). However, various authors have described variations in sweetpotato that cannot simply be explained by genotype $\times$ environmental interactions. Variation occurs for both quantitative traits such as yield, and qualitative traits such as flesh and skin color (Hwang et al., 1983; Steinbauer et al., 1943; Villordon and La Bonte, 1995, 1996). The high ploidy levels should mask some of the mutations, but even so, for flesh color it is estimated that sweetpotato have $1000 \times$ more mutations than tetraploid potato (Solanum tuberosum L.) (Villordon and LaBonte, 1995).

The sweetpotato cultivar White Jewel (PI 634459) is a yellow-and-orange fleshed spontaneous mutant of the cultivar Jewel (PI 566638). Whereas 'Jewel' has a uniform orange flesh color, 'White Jewel' storage roots have a yellow cortex and central parenchymous area with light, blotchy orange in the cambium ring and cork cambium.

The orange and yellow color of sweetpotato flesh is due to the presence of carotenoids. Carotenoids are isoprenoids (also called terpenoids or terpenes). There are two known pathways

Received for publication 6 Mar. 2006. Accepted for publication 2 Aug. 2006. Approved for publication by the director of the Louisiana Agricultural Experiment Station as manuscript number 06-34-0185. The authors would like to thank Michael Cavalier for his help in the laboratory and greenhouse and Gloria McClure for sugar measurements. In addition we also thank Bryon Sosinski and Kornel Burg for making the cDNA clones available, Limei He, Regina Ali, and Joanna Jankowicz for their hard work during development of the sweetpotato ARCS_Sp02 microarray.

1To whom reprint request should be addressed.E-mail address:DLabonte@agcenter. lsu.edu that lead to the synthesis of isopentenyl diphosphate (IPP) and dimethylallyl diphosphate (DMAPP), the five-carbon building blocks of isoprenoid compounds. Synthesis via the mevalonate (MVA) pathway takes place in the cytoplasm (Bach et al., 1999) while the methylerythritol (MEP) pathway [also known as the 1-deoxy-D-xylulose 5-phosphate (DXP) pathway] is located in the plastids (Fig. 1) (Rohdich et al., 2002; Rohmer, 1999). Carotenes are water insoluble and are synthesized and sequestered in plastids (chloroplasts and chromoplasts). The study of mutants has contributed significantly to our current knowledge of carotenoid biosynthesis and storage (Carol et al., 1999; Isaacson et al., 2002; Li et al., 2001; Norris et al., 1995; Paolillo et al., 2004; Park et al., 2002).

$\beta$-carotene is the predominant carotenoid in most American orange-fleshed sweetpotatoes, but in light fleshed types, other carotenes might be the principal carotene type (Hagenimana et al., 1999; Kays, 1992). Carotenoid intake is associated with a range of health benefits for humans (Beatty et al., 2004; Humphrey et al., 1992; Yeum and Russell, 2002). $\beta$-carotene is the most important dietary precursor to vitamin A. Deficiency in vitamin A leads to xerophthalmia, blindness, and premature death in humans (Mayne 1996). It is estimated that vitamin Adeficiency causes 1.2 million deaths per year, mainly in children between 1 and 4 years of age (Humphrey et al., 1992). Several studies have highlighted the potential role of high $\beta$-carotene containing sweetpotato varieties in preventing vitamin A deficiency, particularly in sub-Saharan Africa (Hagenimana et al., 1999; Jalal et al., 1998; Low et al., 2001; van Jaarsveld et al., 2005).

Despite the importance of sweetpotato as a source of $\beta$ carotene, relatively little research has focused on the molecular aspects of $\beta$-carotene synthesis and storage in sweetpotato roots. We aim to elucidate these aspects by comparing global gene expression between 'Jewel' and 'White Jewel' using microarray technology. 


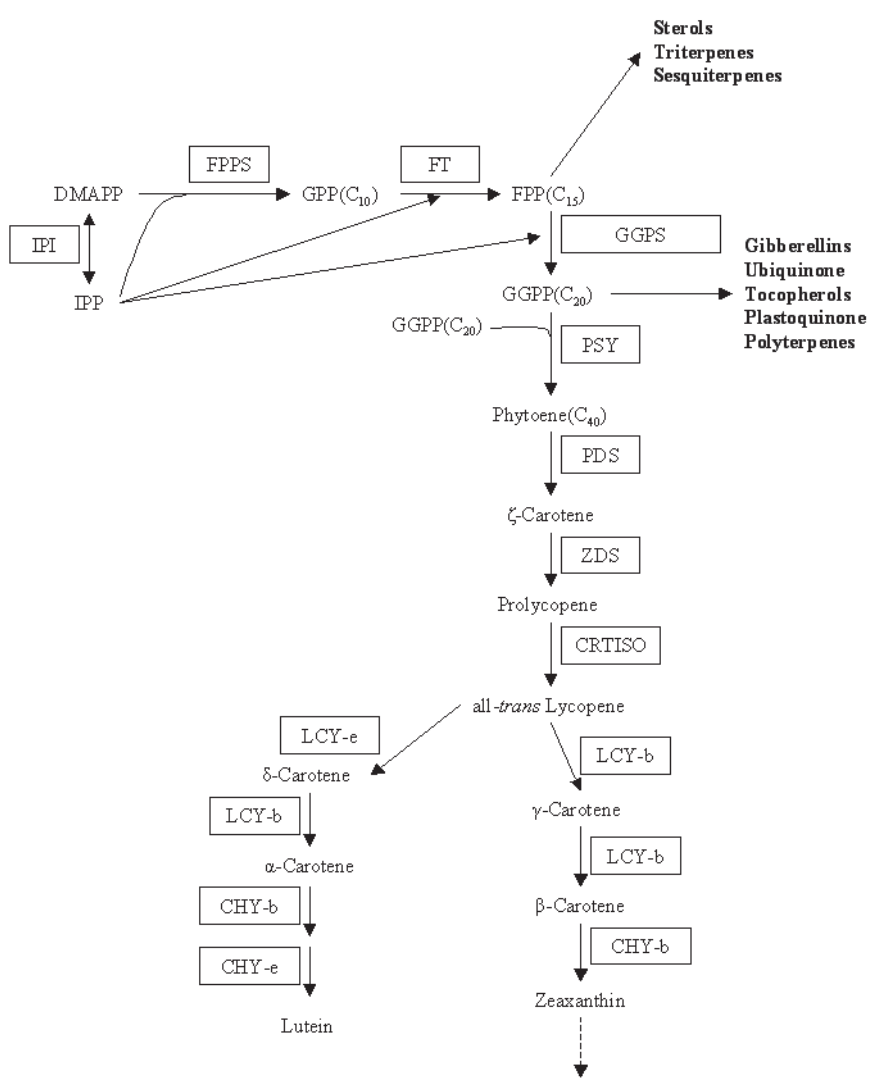

Fig. 1. The carotenoid biosynthetic pathway. DMAPP $=$ dimethylallyl disphosphate, IPP = isopentenyl diphosphate, IPI = isopentenyl diphosphate isomerase, FPPS = farnesyl-diphosphate synthase, GPP = geranyl dihosphate, FT = farnesyltransferase, FPP = farnesyl, GPS = geranylgeranyl diphosphate synthase, GGPP = geranylgeranyl diphosphate, PSY = phytoene synthase, $\mathrm{PDS}=$ phytoene desaturase, $\mathrm{ZDS}=\zeta$-carotene desaturase, $\mathrm{CRTISO}=$ carotene isomerase, LCY-b = lycopene $\beta$-cyclase, LCY-e = lycopene $\varepsilon$-cyclase, CHY-b $=\beta$-ring hydroxylase, $\mathrm{CHY}-\mathrm{e}=\varepsilon$-ring hydroxylase.

\section{Materials and Methods}

Plant materials. Three-leaf shoot cuttings from virus tested sweetpotato cultivars Jewel and White Jewel were transplanted in pots in a temperature-controlled greenhouse. Storage roots from 45 plants of each cultivar were harvested 6 weeks after transplanting (WAT). Storage roots from 15 plants were pooled for each biological replicate and three biological replicates were used in total for each cultivar.

Microarray analysis. Storage roots were ground in a Waring blender (model 33BL79; Dynamics Corp. of America, New Hartford, Conn.) cooled with dry ice, followed by further grinding in a mortar and pestle. RNA extractions were carried out with the RNeasy Maxi Kit (Qiagen, Valencia, Calif.) using lysis buffer RLT, but otherwise following the manufacturers protocol. RNA was further purified and concentrated using the RNeasy Mini Kit (Qiagen). DNase I digestion was carried out on-column following the manufacturers instructions. RNA was extracted twice (technical replicates) from each biological replication, yielding a total of six RNA samples for each cultivar for microarray analysis.

Ten micrograms of total RNA was labeled using the SuperScript Indirect cDNA Labeling System for DNA Microarrays (Invitrogen, Carlsbad, Calif.) according to the manufacturer's protocol. Samples were labeled with Cy3 or Cy5 fluorescent labels (Amersham Biosciences, Piscataway, N.J.) and hybridized onto 12 ARCS_Sp02 arrays in a connected loop design. (Rosa et al. 2005) using the Pronto hybridization kit (Corning, Corning, N.Y.). In the connected loop design a sample from 'Jewel' were labeled with Cy3 and hybridized on an array with a 'White Jewel' sample labeled with Cy5. On the next array, the same 'White Jewel' sample was now labeled with $\mathrm{Cy} 3$ and hybridized on an array together with another 'Jewel' sample labeled with Cy5. This process was continued until all samples were used in the loop (a total of 12 arrays). Arrays were scanned with the AlphaArray Reader (Alpha Innotech, San Leandro, Calif.) and quantified using UCSF Spot (Jain et al., 2002).

The ARCS_Sp02 array contains 2788 sweetpotato cDNAs and 284 control features spotted in triplicate on GAPSII slides (Corning) using a Genemachines Omnigrid microarray printer (GeneMachines, San Carlos, Calif.). Slides were printed and supplied by K. Burg (ARC Seibersdorf Research GmbH, Seibersdorf, Austria) with collaboration from B. Sosinski(Dept. of Horticultural Science, North Carolina State Univ., Raleigh).

Data transformation (log base 2), normalization, and statistical analysis were carried out using The Linear Models for Microarray Data (limma) software package (Smyth, 2005). Within-array loess normalization and between-array aquantile normalization were applied (Smyth and Speed, 2003). Triplicate spots on the array were dealt with using the duplicateCorrelation function (Smyth et al., 2005), while the loop design and technical replicates were handled as suggested by Smyth (2005). Differentially expressed genes were identified using empirical Bayes methods (Smyth, 2004). Genes were considered to be differentially expressed if the $P$ value was smaller than 0.01 after Holm (1979) multiple testing correction. Throughout this paper we will refer to genes with higher expression in 'White Jewel' storage roots as upregulated and genes with higher expression in 'Jewel' roots, as down-regulated.

Putative descriptions for sweetpotato cDNA sequences were obtained by comparing (BLASTX E-value < 1E-5) translated sequences to Arabidopsis thaliana (L.) Heyhn. protein sequences (Garcia-Hernandez et al., 2002) and the NCBI protein database (Gish and States, 1993). Information from the Munich Information Center for Protein Sequences (MIPS) (Schoof et al., 2002) was used to functionally classify genes.

QUANTITATIVE REVERSE TRANSCRIPTION-POLYMERASE CHAIN REACTION (Q-RT-PCR). Nine genes of interest were selected for validation with two-step Q-RT-PCR. The majority of genes were selected as a result of their involvement in carotenoid biosynthesis or the chloroplast (or chromoplast development). CB330166 was selected because it is generally considered a housekeeping gene. First-strand cDNA synthesis was carried out using the SuperScript III First-Strand Synthesis System for RT-PCR (Invitrogen) following the instructions of the manufacturer. The resulting reactions were diluted by adding $40 \mu \mathrm{L}$ water and $1 \mu \mathrm{L}$ of the dilution was used for RT-PCR on the ABI PRISM 7000 Sequence Detection System using SYBR Green PCR Master Mix (Applied Biosystems, Foster City, Calif.) and $600 \mathrm{~nm}$ of each primer in a final volume of $25 \mu \mathrm{L}$. Primers were designed with Primer Express (version 2.0; Applied Biosystems) and the sequences can be found in Table 1 . In addition primers were designed for two recently isolated genes in the carotenoid pathway that were not represented on the array (K. Burg, personal communication) (Table 1). The relative standard curve method as described in the User Bulletin \#2 (Applied Biosystems) were used to obtain relative expression levels for each sample. Dissociation curves were examined to detect nonspecific amplification 
Table 1. Primer sequences used for validation of microarray results with quantitative reverse transcription-polymerase chain reaction. Primers were also designed for two recently isolated genes in the carotenoid pathway (FPPS = farnesyl-diphosphate synthase, LCY-b = lycopene $\beta$-cyclase) that were not represented on the array (K. Burg, personal communication).

\begin{tabular}{lll}
\hline $\begin{array}{l}\text { GeneBank } \\
\text { accession no./gene }\end{array}$ & & \multicolumn{1}{c}{ Primers $\left(5^{\prime} \rightarrow 3^{\prime}\right)$} \\
\hline DV034581 & FWD & TGCAGCCATCCTCTTACCG \\
& REV & TGGGCAGCATTCTCACTCC \\
DV037120 & FWD & GCGGTGGAGATGATCCACAC \\
& REV & CGGAGATCGTCGTTGTCCAT \\
CB330505 & FWD & TTCCCGGTCAGGTTCTCAGA \\
& REV & GGGAGTGACCAAGACGCAGA \\
CB330580 & FWD & CAAATTGCCGAAGCCTATG \\
& REV & AAAAGAGCACAGGTATGACTGGC \\
CB330720 & FWD & TTCTCTCTTCATCTTCGGGTTCC \\
& REV & CCAGGATTACGCCCTGGAT \\
CB330938 & FWD & CCGAGCTCAAGGTGAAGGAG \\
& REV & CTGAACGAAGAAGCCAAACATG \\
CB330113 & FWD & GGGTCCAAGTGTGTGAAGGA \\
& REV & TTTTCCAGAAGCCACCAGCTA \\
DV037363 & FWD & AAGACCACCCTGGGCTCCT \\
& REV & TTCAGCTCCTGCGACACTTG \\
CB330166 & FWD & TGGTCGCTAGGGTTGCTCTG \\
& REV & GAACGGGTCGTTGACTGCA \\
FPPS & FWD & CCCCTACAAGGGTGTAATCAG \\
LCY-b & REV & TCCAAACTGCCAGTGGGC \\
& FWD & TCTGGCAGAAGTGGAGGAACA \\
& REV & GGTGAGAGTCTCGCCAATCC \\
\hline Bens0n & &
\end{tabular}

${ }^{\mathrm{z}}$ Benson et al. (2005).

and 18S ribosomal RNA specific primers (Applied Biosystems) were used for normalization. The same RNA samples used for microarray analysis were used for Q-RT-PCR. Each sample was done in duplicate and technical replicates were averaged to yield a single measurement for each biological replicate that was used for statistical analysis using MINITAB (release 14.1; Minitab, State College, Pa.). Differences were considered statistically significant if $P<0.05$.

Alcohol-Insoluble solids (AIS, CRUde STARCh), SUgar, DRY WEIGHT (DW), AND $\beta$-CAROTENE CONTENT. Six roots were randomly chosen from each pool (biological replicate) for AIS, sugar content and DW determination as described by Picha (1987). Briefly, unpeeled roots were halved and grated to produce two $10-\mathrm{g}$ samples. One sample was homogenized in $80 \%$ ethanol for 1 min using a Brinkman homogenizer (Brinkman Instruments, Westbury, N.Y.) and then boiled for $15 \mathrm{~min}$. After cooling the sample, it was filtered through Whatman no. 4 filter paper. The weight of the insoluble residue on the filter after drying was used to determine AIS content. The filtrate was adjusted to a final volume of $100 \mathrm{~mL}$ and used to determine sugar content using high performance liquid chromatography (HPLC) using a SUPELCOSILTM LC-NH2 column (SUPELCO, Bellefonte, $\mathrm{Pa}$.). The duplicate 10 -g sample was dried at $70{ }^{\circ} \mathrm{C}$ for $48 \mathrm{~h}$ to determine DW.

Four representative roots from each biological replicate were selected for $\beta$-carotene determination. CIE L*, $\mathrm{a}^{*}, \mathrm{~b}^{*}$ (Commission Internationale d'Eclairage) color values were measured for the outside (skin) and a cross-section (flesh) of each root using a Minolta spectrophotometer cm 3500d (Minolta Co., Osaka, Japan). The values of the four roots were averaged to get a value for each biological replicate. $\beta$-carotene content was determined using the following linear regression model described by Takahata et al. (1993): Carotene content $(\mathrm{mg} / 100 \mathrm{~g})=0.864 \mathrm{a}^{*}-8.68$.

Two-sample $t$ tests were used to determine statistical significance of the differences between measurements from 'Jewel' and 'White Jewel' samples using MINITAB (release 14.1; Minitab). Differences were considered statistically significant if $P<0.05$.

\section{Results and Discussion}

Forty genes were differentially expressed between 'Jewel' and 'White Jewel' (Table 2). Of these, 30 genes were downregulated in 'White Jewel' compared to 'Jewel' while 10 were up-regulated. Five genes showed no homology with known genes and two were homologous to "expressed proteins." Fold changes for differentially expressed genes were small, ranging from -1.39 to -1.12 for down-regulated genes and 1.15 to 1.34 for up-regulated genes. A possible cause for this is that the cambium areas of 'White Jewel' are similar to that of 'Jewel' and that this causes a dilution effect. The fold changes are therefore the average for all cells in the root, and it is probable that if the cortex areas of the roots were dissected out, the fold changes of the genes would be larger.

Q-RT-PCR results for eight genes tested were in good agreement with results obtained with microarrays (Table 3). Differential expression of the glyceraldehyde-3-phosphate dehydrogenase gene (CB330166) was not confirmed with Q-RT-PCR analysis.

CIE color measurements, for skin and flesh color of 'Jewel' and 'White Jewel' are given in Fig. 2A and 2B. All differences we statistically significant, except for the skin $L^{*}$ value (Fig. $2 \mathrm{~B})$. The $\beta$-carotene content calculated from flesh $\mathrm{a}^{*}$ color values were $20.66 \mathrm{mg} / 100 \mathrm{~g}$ fresh weight $(\mathrm{FW})$ for 'Jewel' and 1.68 $\mathrm{mg} / 100 \mathrm{~g} \mathrm{FW}$ for 'White Jewel.' Although genes for nearly all the steps in the carotenoid pathway (Fig. 1) have been identified in plants (Cunningham, 2002), only a handful has been isolated in sweetpotato (Burg and Berenyi, 2004). Two genes involved in the $\beta$-carotene pathway, isopentenyl diphosphate isomerase (IPI) and geranyl-geranyl diphosphate synthase (GGPS), are represented on the ARCS_Sp02 array. A gene (DV034581) with homology to plastidal IPI was down-regulated in 'White Jewel' (Table 2 and Fig. 3). During isoprenoid synthesis IPI catalyzes the interconversion of IPP and DMAPP. In the MEP pathway both IPP and DMAPP are produced in the terminal branching step through the action of isopentenyl/dimethylallyl diphosphate synthase (IDDS) (Rodríguez-Concepción and Boronat, 2002; Rohdich et al., 2002). This makes low level isoprenoid biosynthesis possible without IPI, but IPI is required for full function of the pathway (Page et al., 2004). Two genes (DV037120 and CB330462) with homology to GGPS were not differentially expressed between 'White Jewel' and 'Jewel' (DV037120, Fig. 3; CB330462, data not shown). GGPS catalyzes the condensation of (E,E)-farnesyl diphosphate and IPP to produce diphosphate and geranylgeranyl diphosphate (GGPP).

Recently two additional genes in the carotonoid pathway, farnesyl-diphosphate synthase (FPPS) and lycopene $\beta$-cyclase (LCY-b) were isolated in sweetpotato (K. Burg, personal communication). In an effort to investigate as many genes in the pathway as possible, primers were developed from the sequences supplied by K. Burg and expression were measured using Q-RTPCR. Neither of these genes was differentially expressed (Fig. 3). FPPS catalysis a reaction early in the pathwasy, between IPI and 


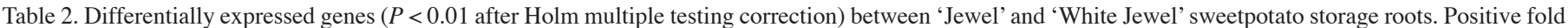
changes indicate up-regulation in 'White Jewel' roots, while negative fold changes indicated down-regulation in 'White Jewel' roots.

\begin{tabular}{|c|c|c|c|c|c|}
\hline $\begin{array}{l}\text { GenBank }^{\mathrm{Z}} \\
\text { accession no. }\end{array}$ & Putative gene description $^{\mathrm{y}}$ & $\begin{array}{c}\text { Fold } \\
\text { change }\end{array}$ & $P$ & Homology & $\mathrm{E}^{\mathrm{x}}$ \\
\hline \multicolumn{6}{|l|}{ Metabolismw $^{w}$} \\
\hline CB330166 & glyceraldehyde-3-phosphate dehydrogenase, cytosolic & -1.17 & $5 \mathrm{E}-10$ & At3g04120.1 & $1 \mathrm{E}-159$ \\
\hline DV035409 & inorganic pyrophosphatase (Nicotiana tabacum L.) & -1.36 & $6 \mathrm{E}-07$ & CAA58701 & $7 \mathrm{E}-84$ \\
\hline DV034581 & isopentenyl diphosphate isomerase 1 ( $N$. tabacum) & -1.23 & $5 \mathrm{E}-03$ & BAB40973 & 1E-97 \\
\hline CB330580 & psbK PSII K protein & 1.29 & $3 \mathrm{E}-10$ & AtCg00070 & $3 \mathrm{E}-19$ \\
\hline CB330897 & sporamin B [Ipomoea batatas (L.) Lam.] & 1.34 & 7E-07 & AAA33390 & $7 \mathrm{E}-38$ \\
\hline DV034610 & sucrose synthase 2 (Solanum tuberosum L.) & -1.27 & 7E-06 & AAO34668 & 2E-90 \\
\hline CB330358 & triosephosphate isomerase, cytosolic, putative & -1.29 & 2E-05 & At3g55440.1 & $1 \mathrm{E}-109$ \\
\hline \multicolumn{6}{|l|}{ Energy } \\
\hline CB329982 & ATP synthase epsilon subunit (I. batatas) & 1.16 & 3E-03 & CAD23965 & $9 \mathrm{E}-66$ \\
\hline \multirow[t]{2}{*}{ CB330938 } & light harvesting chlorophyll a/b-binding protein & & & & \\
\hline & (Nicotiana sylvestris Pflanzl.) & -1.20 & 8E-04 & BAA25392 & $3 \mathrm{E}-133$ \\
\hline CB330113 & cytochrome c oxidase subunit Vc family protein & -1.13 & 5E-04 & At $2 \mathrm{~g} 47380.1$ & $4 \mathrm{E}-22$ \\
\hline CB330505 & photosystem II oxygen-evolving complex 23 (OEC23) & -1.19 & 1E-03 & At1g06680.1 & $1 \mathrm{E}-110$ \\
\hline CB330720 & photosystem II protein I (Ranunculus macranthus Scheele) & 1.26 & 8E-08 & AAZ04048 & $3 \mathrm{E}-14$ \\
\hline \multicolumn{6}{|c|}{ Protein synthesis and fate } \\
\hline CB330804 & cathepsin B-like cysteine protease, putative & -1.18 & 2E-03 & At1g02305.1 & $1 \mathrm{E}-106$ \\
\hline DV037272 & chaperonin & 1.17 & 7E-04 & At3g18190.1 & $4 \mathrm{E}-37$ \\
\hline CB330700 & elongation factor 1-alpha / EF-1-alpha & -1.18 & 5E-03 & At5g60390.1 & $1 \mathrm{E}-72$ \\
\hline CB330102 & polyubiquitin (UBQ10) & -1.21 & $3 \mathrm{E}-03$ & At4g05320.5 & $2 \mathrm{E}-77$ \\
\hline CB330932 & ubiquitin extension protein 1 (UBQ1) & -1.14 & 5E-03 & At3g52590.1 & $1 \mathrm{E}-65$ \\
\hline \multicolumn{6}{|l|}{ Transcription } \\
\hline DV035522 & bZIP transcription factor family protein & -1.22 & 7E-03 & At3g30530.1 & $2 \mathrm{E}-24$ \\
\hline \multirow[t]{2}{*}{ CB330144 } & remorin 1 , putative [Oryza sativa $\mathrm{L}$. & & & & \\
\hline & (japonica cultivar-group)] & -1.19 & 8E-03 & XP_466996 & $8 \mathrm{E}-37$ \\
\hline \multicolumn{6}{|l|}{ Transport } \\
\hline CB330336 & ADP-ribosylation factor & -1.22 & $4 \mathrm{E}-07$ & At3g62290.1 & $3 \mathrm{E}-28$ \\
\hline CB330838 & aquaporin (PIP1.3) & -1.31 & 3E-08 & At1g01620.1 & $1 \mathrm{E}-144$ \\
\hline \multicolumn{6}{|c|}{ Biogenesis of cellular components } \\
\hline \multicolumn{6}{|l|}{ CB330125/ } \\
\hline \multirow[t]{2}{*}{ CB330126v } & alpha tubulin 1 [Pseudotsuga menziesii (Mirbel) & & & & \\
\hline & Franco var. menziesii] & -1.20 & 4E-04 & AAV92379 & 4E-91 \\
\hline \multirow[t]{2}{*}{ CB330258 } & lipocalin, temperature-induced (Lycopersicon & & & & \\
\hline & esculentum Mill.) & -1.23 & 2E-05 & ABB02390 & 3E-77 \\
\hline \multicolumn{6}{|c|}{ Cell cycle and DNA processing } \\
\hline DV036591 & DNAJ heat shock protein, putative (J3) & -1.18 & 2E-03 & At $3 g 44110.1$ & $6 \mathrm{E}-57$ \\
\hline \multicolumn{6}{|c|}{ Cell rescue, defense and virulence } \\
\hline DV037363 & gp91-phox, whitefly-induced (L. esculentum) & 1.15 & 4E-04 & AAF73124 & $9 \mathrm{E}-16$ \\
\hline CB330013 & metallothionein-like type 1 protein (I. batatas) & -1.17 & 2E-04 & BAD95644 & $3 \mathrm{E}-79$ \\
\hline CB330561 & thioredoxin peroxidase (Capsicum annuиm L.) & -1.12 & 9E-03 & AAL35363 & $2 \mathrm{E}-75$ \\
\hline \multicolumn{6}{|c|}{ Cellular communication/signal transduction mechanism } \\
\hline DV035500 & CTR1-like protein kinase (L. esculentum) & 1.16 & 2E-04 & AAR89822 & $6 \mathrm{E}-107$ \\
\hline \multirow[t]{2}{*}{ CB329975 } & cyclophilin / peptidyl-prolyl cis-trans isomerase, & & & & \\
\hline & cytosolic / rotamase $(\mathrm{ROC} 3)$ & -1.14 & 9E-03 & At $2 \mathrm{~g} 16600.1$ & $4 \mathrm{E}-78$ \\
\hline CB330481 & cyclophilin-like (S. tuberosum) & -1.14 & 7E-04 & ABB29940 & $3 \mathrm{E}-80$ \\
\hline DV034921 & protein phosphatase $2 \mathrm{C}$ family protein & -1.27 & 5E-08 & At1g07630.1 & $6 \mathrm{E}-35$ \\
\hline \multicolumn{6}{|l|}{ Unclassified } \\
\hline CB329950 & allergen-like protein BRSn20 (Sambucus nigra L.) & -1.23 & $8 \mathrm{E}-05$ & AAF16869 & 1E-39 \\
\hline \multirow[t]{2}{*}{ CB330730 } & early nodulin ENOD18 family protein / universal & & & & \\
\hline & stress protein (USP) family protein & -1.22 & 2E-04 & At $3 g 03270.2$ & $3 \mathrm{E}-43$ \\
\hline Unknown & & & & & \\
\hline DV035353 & expressed protein & -1.39 & 3E-06 & At5g49100.1 & $2 \mathrm{E}-30$ \\
\hline DV034897 & expressed protein (in thylakoid lumen) & -1.23 & 1E-03 & At3g29240.2 & $6 \mathrm{E}-63$ \\
\hline CB330777 & no homology & 1.32 & 2E-05 & & \\
\hline CB329930 & no homology & 1.28 & 8E-04 & & \\
\hline DV034780 & no homology & 1.15 & $8 \mathrm{E}-03$ & & \\
\hline CB330067 & no homology & -1.12 & $6 \mathrm{E}-03$ & & \\
\hline CB330200 & no homology & 1.17 & 9E-03 & & \\
\hline
\end{tabular}

${ }^{z}$ Benson et al., 2005

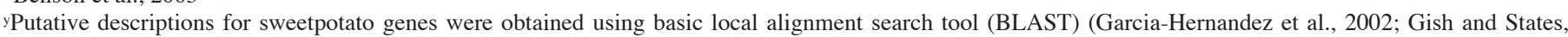
1993).

xExpectation value. The lower the E value, the more significant the score.

wFunctional classification was done according to the Munich Information Center for Protein Sequences (Schoof et al., 2002).

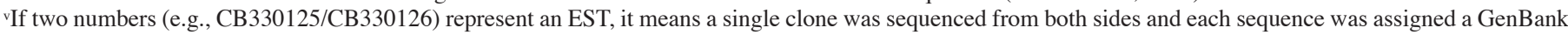
accession number, but it represents only one feature (spot) on the array. 
Table 3. Comparison of results obtained for nine genes with microarray analysis and quantitative reverse transcriptionpolymerase chain reaction (Q-RT-PCR). Positive fold changes (FC) indicate up-regulation in 'White Jewel' sweetpotato storage roots, while negative fold changes indicate down-regulation. Numbers in bold indicate fold changes that are statistically significant.

\begin{tabular}{|c|c|c|c|c|c|}
\hline \multirow{2}{*}{$\begin{array}{l}\text { GenBank }^{\mathrm{z}} \\
\text { accession no. }\end{array}$} & \multicolumn{2}{|c|}{ Microarray } & \multicolumn{2}{|c|}{ Q-RT-PCR } & \multirow[b]{2}{*}{ Homology ${ }^{y}$} \\
\hline & $\mathrm{FC}$ & $P$ & $\mathrm{FC}$ & $P$ & \\
\hline$\overline{\text { DV034581 }}$ & -1.23 & 0.005 & -1.99 & 0.036 & isopentenyl diphosphate isomerase (IPI) \\
\hline DV037120 & -1.03 & 1.000 & 1.03 & 0.66 & geranylgeranyl diphosphate synthase (GGPS) \\
\hline CB330505 & -1.19 & 0.001 & $-\mathbf{1 . 3 8}$ & 0.027 & photosystem II oxygen-evolving complex 23 \\
\hline CB330580 & 1.29 & 0.000 & 2.15 & $\mathbf{0 . 0 3 0}$ & psbK PSII K protein \\
\hline CB330720 & 1.26 & 0.000 & 1.96 & 0.003 & photosystem II protein I \\
\hline CB330938 & -1.20 & 0.001 & -1.61 & 0.012 & light harvesting chlorophyll a/b-binding protein \\
\hline CB330113 & -1.13 & 0.001 & -1.21 & 0.042 & cytochrome c oxidase subunit Vc family protein \\
\hline DV037363 & 1.15 & 0.000 & 3.31 & 0.000 & gp91-phox, whitefly-induced \\
\hline CB330166 & $-\mathbf{1 . 1 7}$ & 0.000 & -1.20 & 0.143 & glyceraldehyde-3-phosphate dehydrogenase, cytosolic \\
\hline
\end{tabular}

${ }^{\mathrm{z}}$ Benson et al. (2005).

${ }^{y}$ Putative descriptions for sweetpotato genes were obtained using basic local alignment search tool (BLAST) (GarciaHernandez et al., 2002; Gish and States, 1993).
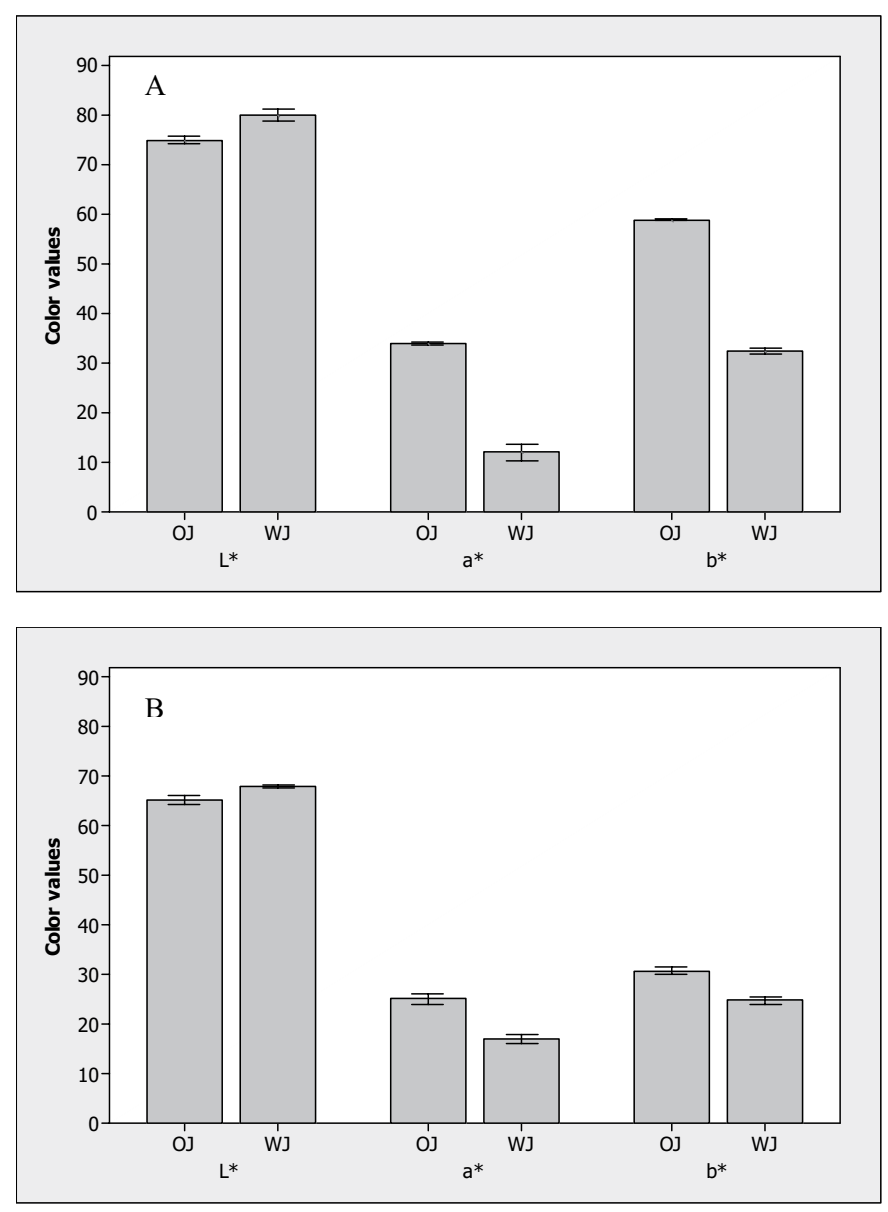

Fig. 2. CIE color values measured for (A) flesh and (B) skin color of sweetpotato storage roots from 'Jewel' (OJ) and 'White Jewel' (WJ); L* = lightness, $\mathrm{a}^{*}=$ red-green, $\mathrm{b}^{*}=$ blue-yellow; bars indicate SE.

GGPS. The nondifferential expression of GGPS and FPPS is not totally unexpected. FPP and GGPP are precursors of a wide range of isoprenoids (Fig. 1). In the plastid these include carotenoids, gibberellins, tocopherols, chlorophylls, and phylloquinones. LCY-b catalyses the formation of $\beta$-carotene from lycopene and the formation of $\alpha$-carotene from $\delta$-carotene. The nondifferential expression of LCY-b might therefore be related to $\alpha$-carotene and lutein synthesis. Ducreux et al. (2005) reported higher $\beta$-carotene

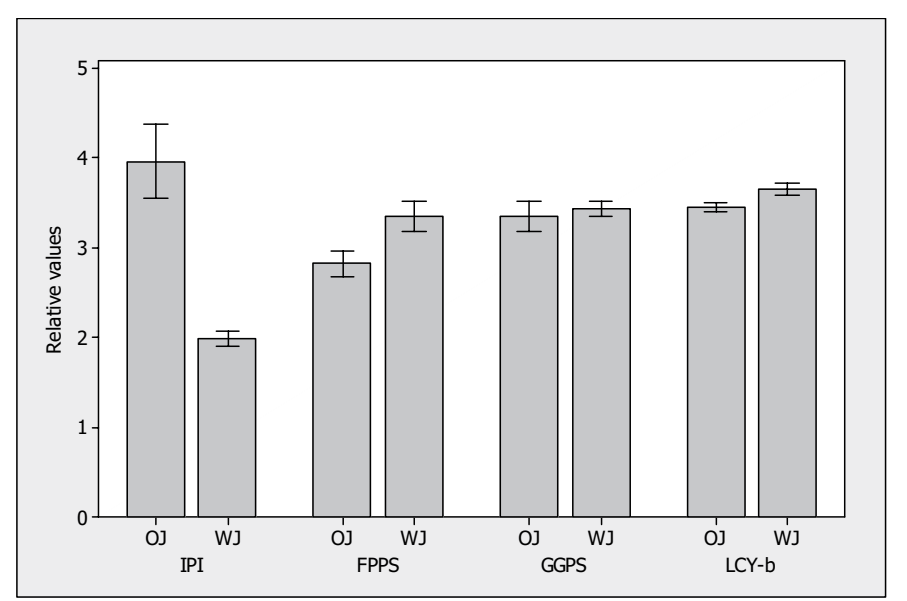

Fig. 3. Relative expression values of isopentenyl diphosphate isomerase (IPI), farnesyl-diphosphate synthase (FPPS), geranylgeranyl diphosphate synthase (GGPS), and lycopene $\beta$-cyclase (LCY-b) in sweetpotato storage roots of 'Jewel' (OJ) and 'White Jewel' (WJ) determined by quantitative reverse transcriptionpolymerase chain reaction. Relative expression levels were statistically significantly different $(P<0.05)$ for IPI; bars indicate SE.

and lutein levels in S. tuberosum tubers transformed with pytoene synthase, but nondifferential expression of LCY-b between transformed and untransformed plants. It therefore seems that LCY-b expression is not a rate-limiting step in this pathway.

It should also be kept in mind that different forms exist for several genes in the carotenoid pathway. For example 11 members of the GGPS family have been identified in A. thaliana (Cunningham, 2002). Our study does not represent a comprehensive picture of carotenoid biosynthesis in sweetpotato. However to our knowledge it is the first study to investigate the expression of genes in this pathway in sweetpotato. Phytoene synthase (PSY) have been shown to be a key rate-limiting enzyme in the carotenoid pathway (Taylor and Ramsey, 2005). A substantial increase in $\beta$ carotene levels was observed in tomato (Lycopersicon esculentum Mill.) fruit (Fraser et al., 2002), canola (Brassica napus L.) seed (Shewmaker et al., 1999), A. thaliana seed (Lindgren et al., 2003), and S. tuberosum tubers (Ducreux et al., 2005) after over-expression of PHY. PHY have not been isolated in sweetpotato despite recent efforts (Burg and Berenyi, 2004). For further studies of the very important carotenoid pathway in sweetpotato, it is essential that efforts to isolate this key gene should continue. 
Several genes associated with the chloroplast and the photosynthetic apparatus were differentially expressed between 'Jewel' and 'White Jewel' (Table 2). A gene (CB330938) with homology to light harvesting chlorophyll a/b-binding protein and one (CB330505) with homology to photosystem II oxygen-evolving complex 23 were down regulated in 'White Jewel'. A 23-kDa oxygen-evolving-complex-like protein has been implicated in a respiratory redox chain linked to phytoene desaturation in daffodil (Narcissus pseudonarcissus L.) (Nievelstein et al., 1995). A gene (CB330580) with homology to psbK (PSII K) protein and one (CB330720) with homology to photosystem II protein I were upregulated in 'White Jewel'. Carrotenoids are water-insoluble and in nonphotosynthetic tissue carotenoids accumulate in dedicated lipoprotein-sequestering structures in chromoplasts (Bartley and Scolnik, 1995; Vishnevetsky et al., 1999). During fruit ripening and flower development, chromoplasts are often derived from fully developed chloroplasts (Marano et al., 1993; Whatley and Whatley, 1987). During this transition the photosynthetic apparatus, including the thylakoid membranes are broken down (Livne and Gepstein, 1988; Piechulla et al., 1987). Our results seem to indicate differences between the chromoplast development of 'Jewel' and 'White Jewel'. Previous studies have indicated that sequestering of carotene in chromoplast (lipoprotein structures) is more strongly related with carotenoid buildup than expression levels of genes in the carotenoid biosynthetic pathway (Al-Babili et al., 1996; Deruere et al., 1994; Howitt and Pogson, 2006; Li et al., 2001; Paolillo et al., 2004; Pozueta-Romero et al., 1997; Rabbani et al., 1998; Vishnevetsky et al., 1996).

Practically nothing is known about sweetpotato chromoplasts and their development. Present knowledge of chromoplast development has focused on studies of fruits and flower petals, where chromoplasts develop from chloroplasts. However, in Daucus carota L. roots, chromoplasts develop from nonphotosynthetic plastids (Marano et al., 1993). One would expect that chromoplasts in sweetpotato would follow a similar developmental process. At this stage it is unclear how the differential expression of chloroplast-related genes relate to chromoplast development in sweetpotato. The differential expression of chloroplast-associated genes between 'Jewel' and 'White Jewel' roots indicate putative differences in the plastids in these roots. However at this stage it is not possible to make definitive conclusions about chromoplast development. Light and electron microscopy studies of sweetpotato chromoplasts are sorely needed and would yield insight into this important aspect of carotene content of sweetpotato roots.

Interestingly, Park et al. (2002) showed that chlorophylls and carotenoids themselves play an important role in chloroplast development. In a very elegant series of experiments using virusinduced gene silencing (VIGS), Page et al. (2004) showed disruption of plastids in leaves of plants where IPI has been silenced. In the current study we observed down-regulation of IPI in 'White Jewel' and differential expression of chloroplasts-related genes. However it is not possible to determine cause and effect clearly. The leaves in the Page et al. (2004) study had a mottled, palewhite appearance, while the expression of $\beta$-carotene in 'White Jewel' is more defined, with some accumulation in the cambium area, but very little (or none) in the cortex region. The $\beta$-carotene pathway is still functioning in 'White Jewel' as can be seen by the orange color of the cambium region. The mutation affects mainly the cortex and central parenchymaous regions. A mutation associated with tissue specific accumulation of $\beta$-carotene has been described in cauliflower (Brassica oleracea L. var. botrytis L.) (Li et al., 2001; Paolillo et al., 2004). No dramatic changes were observed in expression of genes involved in the $B$. oleracea carotenoid pathway, but structural modifications that allow $\beta$-carotene accumulation were observed in plastids of the mutant. This mutation did not affect carotenoid composition in leaves of flowers.

The signals and mechanisms that regulate carotenogenesis are still largely unknown. Reactive oxygen species (ROS) have been implicated as secondary messengers of this process in bell pepper (Capsicum annuum L.) (Bouvier et al., 1998). It is thought that the regulation of carotenoids by ROS is related to the protection that extended chromophores provide against oxidative stresses. Two genes related to ROS regulation, thioredoxin peroxidase (CB330561) and gp91-phox (DV037363), were differentially expressed between 'Jewel' and 'White Jewel'. Thioredoxin peroxidase is a ROS scavenger, while gp91-phox is part of the NADPH oxidase complex. NADPH oxidase contributes to production of ROS and gp91-phox is induced by hydrogen peroxide in A. thaliana suspension cultures (Desikan et al., 1998). Since thioredoxin peroxidase is down-regulated in 'White Jewel' and gp91-phox is up-regulated, a higher level of ROS is implicated in 'White Jewel'. However in the Bouvier et al. (1998) study, oxidative stress was associated with an increase in carotenoid synthesis in C. anпиит. The differential expression of gp91-phox is surprising since NADPH oxidase is usually associated with pathogens or environmental stresses (Mittler, 2002). Since chromoplasts in $C$. аnпииm originate from actively photosynthesizing tissue (a source of ROS) and sweetpotato chromoplasts do not, it is possible that the effects of ROS on carotenoid synthesis in these tissues are different. Differences in the regulation of carotenogenesis and chromoplast development in fruits and flowers have been observed, particularly the involvement of phytohormones in flowers (Vishnevetsky et al., 1999).

Fructose and glucose levels were significantly lower in 'White Jewel' than 'Jewel' (Fig. 4). However, sucrose levels were higher in 'White Jewel'. In sweetpotato roots, sucrose is degraded via sucrose synthase (Susy) to produce UDP-glucose and fructose (Li andZhang, 2003), which are then converted to hexose-phosphates used for starch synthesis in the amyloplasts. The lower fructose and glucose levels, and higher sucrose levels observed in 'White Jewel' are in agreement with the observed down-regulation of a gene (DV034610) with homology to SuSy. These observations raises the question whether more starch is produced in 'Jewel'

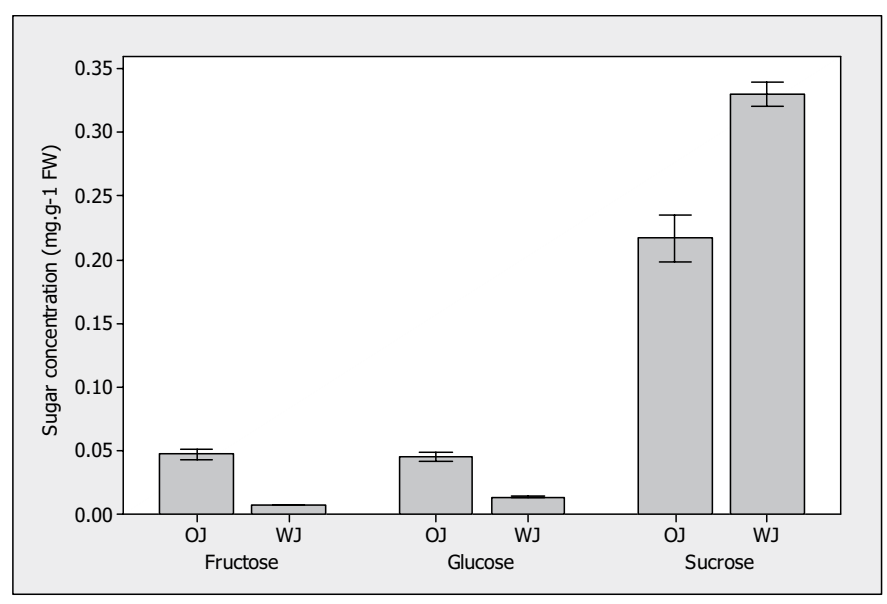

Fig. 4. Sugar content of sweetpotato storage roots from 'Jewel' (OJ) and 'White Jewel' (WJ) given in milligrams per gram fresh weight (FW); bars indicate SE. 


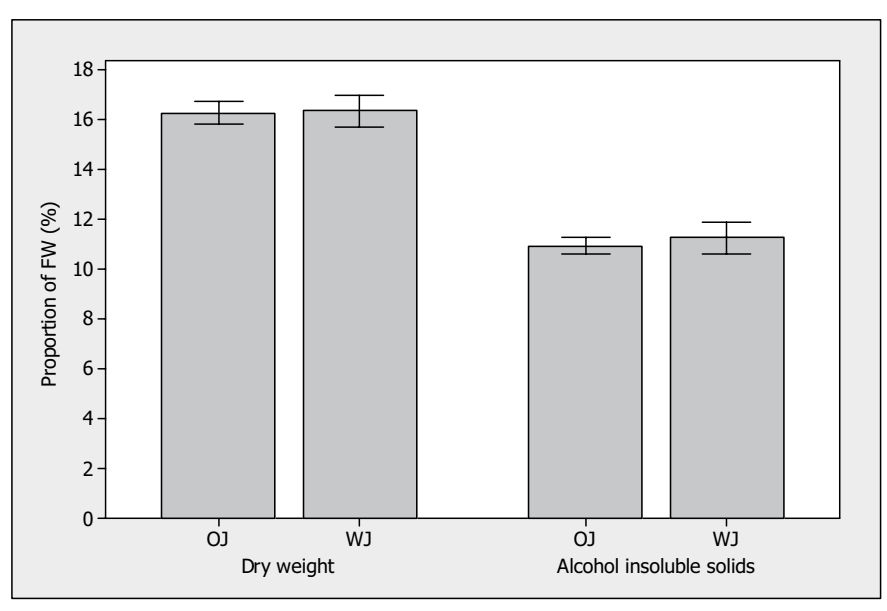

Fig. 5. Dry weight and Alcohol-insoluble solids (AIS) as proportion of fresh weight of sweetpotato storage roots from 'Jewel' (OJ) and 'White Jewel' (WJ); bars indicate SE.

since more fructose and glucose are available for starch synthesis. However, no significant differences were observed between dry weight or AIS of 'Jewel' and 'White Jewel' (Fig. 5). LaBonte et al. (2000) observed variations in fructose and glucose levels of 'Jewel' storage roots during root development (7 to 19 WAT), but a steady increase in sucrose during this period. Interestingly they also found that the two cultivars ('Travis' and 'Beauregard') with the highest glucose and fructose levels also had the lowest DW and AIS levels. It seems therefore that the amount of starch (measured as AIS) is not related to the measured amount of glucose and fructose. These observations are in agreement with observations in $S$. tuberosum, where several studies have shown that elevated levels of hexose-phosphates do not translate to increased starch production (Geigenberger, 2003; Trethewey et al., 1998). Also, since no significant difference was observed between AIS of 'White Jewel' and 'Jewel' it seems that the mutation does not affect amyloplast development in storage roots.

Our study represents the first effort to elucidate $\beta$-carotene synthesis and storage in sweetpotato at the molecular level. Of the four genes in the carotenoid biosynthetic pathway examined, only IPI were differentially expressed. However the differential expression of plastid-related genes point to putative differences in plastid development between 'Jewel' and 'White Jewel'. This underscores recent observations in other plants that plastid development plays an important role in carotenoid content of tissues. Future research should include isolation of all the genes of the carotenoid biosynthetic pathway in sweetpotato, and microscopic studies of chromoplast development in sweetpotatoes with different $\beta$-carotene contents.

\section{Literature Cited}

Al-Babili, S.V., J. Lintig, H. Haubruck, and P. Beyer. 1996. A novel, soluble form of phytoene desaturase from Narcissus pseudonarcissus chromoplasts is Hsp70-complexed and competent for flavinylation, membrane association and enzymatic activation. Plant J. 9:601-612.

Bach, T.J., A. Boronat, N. Campos, A. Ferrer, and K-U. Vollack. 1999. Mevalonate biosynthesis in plants. Crit. Rev. Biochem. Mol. Biol. 34:107-122.

Bartley, G.E. and P.A. Scolnik. 1995. Plant carotenoids: Pigments for photoprotection, visual attraction, and human health. Plant Cell 7:1027-1038

Beatty, S., J. Nolan, H. Kavanagh, and O. O’Donovan. 2004. Macular pigment optical density and its relationship with serum and dietary levels of lutein and zeaxanthin. Arch Biochem. Biophys. 430:70-76.

Benson, D.A., I. Karsch-Mizrachi, D.J. Lipman, J. Ostell, and D.L. Wheeler. 2005. GenBank. Nucl. Acids Res. 33(database issue): D34-D38.

Bouvier, F., R.A. Backhaus, and B. Camara. 1998. Induction and control of chromoplast-specific carotenoid genes by oxidative stress. J. Biol. Chem. 273:30651-30659.

Burg, K. and M. Berenyi. 2004. Study of $\beta$-carotene genes. Genetic diversity of sweetpotato-Progress report 4/2003-3/2004. pp. 68-71. 29Jan. 2006. <http://mcknight.ccrp.cornell.edu/ccrpE/program_docs/ project_documents/spk/SPK_progressrep_03-04_yr2_2jun04.pdf $>$.

Carol, P., D. Stevenson, C. Bisanz, J. Breitenbach, G. Sandmann, R. Mache, G. Coupland, and M. Kuntz. 1999. Mutations in the arabidopsis gene IMMUTANS cause a variegated phenotype by inactivating a chloroplast terminal oxidase associated with phytoene desaturation. Plant J. 11:57-68.

Cunningham, Jr., F.X. 2002. Regulation of carotenoid synthesis and accumulation in plants. Pure Appl. Chem. 74(8):1409-1417.

Deruere, J., S. Romer, A. d'Harlingue, R.A. Backhaus, M. Kuntz, and B. Camara. 1994. Fibril assembly and carotenoid overaccumulation in chromoplasts: A model for supramolecular lipoprotein structures. Plant Cell 6:119-133.

Desikan, R., E.C. Burnett, J.T. Hancock, and S.J. Neill. 1998. Harpin and hydrogen peroxide induce the expression of a homologue of gp91-phox in Arabidopsis thaliana suspension cultures. J. Expt. Bot. 49:1767-1771.

Ducreux, L.J.M., M.L. Morris, P.E. Hedley, T. Shepherd, H.V. Davies, S. Millam, and M.A. Taylor. 2005. Metabolic engineering of high carotenoid potato tubers containing enhanced levels of $\beta$-carotene and lutein. J. Expt. Bot. 56:81-89.

Fraser, P.D., S. Romer, C.A. Shipton, P.B. Mills, J.W. Kiano, N. Misawa, R.G. Drake, W. Schuch, and P.M. Bramley. 2002. Evaluation of transgenic L.esculentum plants expressing an additional phytoene synthase in a fruit-specific manner. Proc. Natl. Acad. Sci. USA 99:1092-1097.

Garcia-Hernandez, M., T.Z. Berardini, G. Chen, D. Crist, A. Doyle, E. Huala, E. Knee, M. Lambrecht, N. Miller, L.A. Mueller, S. Mundodi, L. Reiser, S.Y. Rhee, R. Scholl, J. Tacklind, D.C. Weems, Y. Wu, I. Xu, D. Yoo, J. Yoon, and P. Zhang. 2002. TAIR: A resource for integrated arabidopsis data. Functional Integrative Genomics 2(6):239-253.

Geigenberger, P. 2003. Regulation of sucrose to starch conversion in growing potato tubers. J. Expt. Bot. 54:457-465.

Gish, W. and D.J. States. 1993. Identification of protein coding regions by database similarity search. Nature Genet. 3:266-272.

Hagenimana, V., E.E. Carey, S.T. Gichuki, M.A. Oyunga, and J.K. Imungi. 1999. Carotenoid contents in fresh dried and processed sweetpotato products. Ecol. Food Nutr. 37:455-473.

Holm, S. 1979. A simple sequentially rejective Bonferroni test procedure. Scandinavian J. Stat. 6:65-70.

Howitt, C.A. and B.J. Pogson. 2006. Carotenoid accumulation and function in seeds and non-green tissues. Plant Cell Environ. 29:435-445.

Humphrey, J.H., K.P. West, Jr., and A.V. Sommer. 1992. Vitamin A deficiency and attributable mortality amongst 5-year-olds. World Health Organization Bul. 70:225-232.

Hwang, L.S., R.M. Skirvin, J. Casyao, and J. Bouwkamp. 1983. Adventitious shoot formation from sections of sweetpotato grown in vitro. Scientia Hort. 20:119-129.

Isaacson, T., G. Ronen, D. Zamir, and J. Hirschberg. 2002. Cloning of tangerine from tomato reveals a carotenoid isomerase essential for production of beta-carotene and xanthophylls in plants. Plant Cell 14:333-342.

Jain, A.N., T.A. Tokuyasu, A.M. Snijders, R. Segraves, D.G. Albertson, and D. Pinkel. 2002. Fully automatic quantification of microarray data. Genome Res. 12:325-332.

Jalal, F., M.C. Nesheim, Z. Agus, D. Sanjur, and J.P. Habicht. 1998. Serum retinol concentrations in children are affected by food sources of $\beta$-carotene, fat intake, and anthelmintic drug treatment. Amer. J. Clinical Nutr. 68:623-629. 
Kays, S.J. 1992. The chemical composition of sweetpotato, p. 201-262. In: W.A.Hill, C.K. Bonsi, and P.A. Loretan (eds.). Sweetpotato technology for the 21st century. Tuskegee Univ., Tuskegee, Ala.

LaBonte, D.R., D.H. Picha, and H.A. Johnson. 2000. Carbohydraterelated changes in sweetpotato storage roots during development. J. Amer. Soc. Hort. Sci. 125:200-204.

Li, L., D.J. Paolillo, M.V. Parthasarathy, E.M. DiMuzio, and D.F. Garvin. 2001. A novel gene mutation that confers abnormal patterns of $\beta$-carotene accumulation in cauliflower (Brassica oleracea var. botrytis). Plant J. 26:59-67.

Li, X-Q. and D. Zhang. 2003. Gene expression activity and pathway selection for sucrose metabolism in developing storage root of sweetpotato. Plant Cell Physiol. 44:630-636.

Lindgren, L.O., K.G. Stalberg, and A.S. Hoglund. 2003. Seed-specific overexpression of an endogenous Arabidopsis phytoene synthase gene results in delayed germination and increased levels of carotenoids, chlorophyll, and abscisic acid. Plant Physiol. 132:779-785.

Livne, A. and S. Gepstein. 1988. Abundance of the major chloroplast polypeptides during development and ripening of tomato fruits. Plant Physiol. 87:239-243.

Low, J., T. Walker, and R. Hijmans. 2001. The potential impact of orange-fleshed sweet potatoes on vitamin A intake in Sub-Saharan Africa. The VITAA Project, vitamin A and orange-fleshed sweetpotatoes in Sub-Saharan Africa, 9-11 May 2001, Nairobi, Kenya. 29 Jan. 2006. $<$ http://www.cipotato.org/vitaa/Publications/Paper_vitaa.pdf $>$.

Marano, M.R., E.C. Serra, E.G. Orellano, and N. Carrillo. 1993. The path of chromoplast development in fruits and flowers. Plant Sci. 94:1-17.

Mayne, S.T. 1996. $\beta$-carotene, carotenoids and disease prevention in humans. Federation Amer. Soc. Expt. Biol. J. 10:690-701.

Mittler, R. 2002. Oxidative stress, antioxidants and stress tolerance. Trends Plant Sci. 7:405-410.

Nievelstein, V., J. Vandekerckove, M.H. Tadros, J. vonLintig, W. Nitschke, and P. Beyer. 1995. Carotene desturation is linked to a respiratory redox pathway in Narcissus pseudonarcissus chromoplast membranes: Involvement of a 23-kDa oxygen-evolving-complex-like protein. Eur. J. Biochem. 233:864-872.

Norris, S.R., T.R. Barrette, and D. DellaPenna. 1995. Genetic dissection of carotenoid synthesis in arabidopsis defines plastoquinone as an essential component of phytoene desaturation. Plant Cell 7:2139-2149.

Page, J.E., G. Hause, M. Raschke, W. Gao, J. Schmidt, M.H. Zenk, and T.M. Kutchan. 2004. Functional analysis of the final steps of the 1deoxy-D-xylulose 5-phosphate (DXP) pathway to isoprenoids in plants using virus-induced gene silencing. Plant Physiol. 134:1401-1413.

Paolillo, Jr., D.J., D.F. Garvin, and M.V. Parthasarathy. 2004. The chromoplasts of Or mutants of cauliflower (Brassica oleracea L. var. botrytis). Protoplasma 224:245-253.

Park, H., S.S. Kreunen, A.J. Cuttriss, D. DellaPenna, and B.J. Pogson. 2002. Identification of the carotenoid isomerase provides insight into carotenoid biosynthesis, prolamellar body formation, and photomorphogenesis. Plant Cell 14:321-332.

Picha, D.H. 1987. Carbohydrate changes in sweetpotato during curing and storage. J. Amer. Soc. Hort. Sci. 112:89-92.

Piechulla, B., R.E. Glick, H. Bahl, A. Melis, and W. Gruissem. 1987. Changes in photosynthetic capacity and photosynthetic protein pattern during tomato fruit ripening. Plant Physiol. 84:911-917.

Pozueta-Romero, J., F. Rafia, G. Houlne, C. Cheniclet, J.P. Carde, M.L. Schantz, and R. Schantz. 1997. A ubiquitous plant housekeeping gene, PAP, encodes a major protein component of bell pepper chromoplasts. Plant Physiol. 115:1185-1194.

Rabbani, S., P.V. Beyer, J. Lintig, P. Hugueney, and H. Kleinig. 1998. Induced $\beta$-carotene synthesis driven by triacylglycerol deposition in the unicellular alga Dunaliella bardawil. Plant Physiol. 116:1239-1248.

Rodríguez-Concepción, M. and A. Boronat. 2002. Elucidation of the methylerythritol phosphate pathway for isoprenoid biosynthesis in bacteria and plastids. A metabolic milestone achieved through genomics. Plant Physiol. 130:1079-1089.

Rohdich, F., S. Hecht, K. Gartner, P. Adam, C. Krieger, S. Amslinger, D.
Arigoni, A. Bacher, and W. Eisenreich. 2002. Studies on the nonmevalonate terpene biosynthetic pathway: Metabolic role of IspH (LytB) protein. Proc. Natl. Acad. Sci. USA 99:1158-1163.

Rohmer, M. 1999. The discovery of a mevalonate-independent pathway for isoprenoid biosynthesis in bacteria, algae and higher plants. Natural Product Rept. 16:565-574.

Rosa, G.J.M., J.P. Steibel, and R.J. Tempelman. 2005. Reassessing design and analysis of two-colour microarray experiments using mixed effects models. Comparative Functional Genomics 6:123-131.

Schoof, H., P. Zaccaria, H. Gundlach, K. Lemcke, S. Rudd, G. Kolesov, R. Arnold, H.W. Mewes, and K.F. Mayer. 2002. MIPS Arabidopsis thaliana Database (MAtDB): An integrated biological knowledge resource based on the first complete plant genome. Nucleic Acids Res. 30:91-93.

Shewmaker, C.K., J.A. Sheehy, M. Daley, S. Colburn, and D.Y. Ke. 1999. Seed-specific overexpression of phytoene synthase: Increase in carotenoids and other metabolic effects. Plant J. 20:401-412.

Smyth, G.K. 2004. Linear models and empirical Bayes methods for assessing differential expression in microarray experiments. Stat. Applications Genet. Mol. Biol. 3(1):article 3. 7 Mar. 2006. <http://www. bepress.com/sagmb/vol3/iss 1/art3/>.

Smyth, G.K. 2005. Limma: Linear models for microarray data, p. 397-420. In: R. Gentleman, V. Carey, S. Dudoit, R. Irizarry, and W. Huber (eds.). Bioinformatics and computational biology solutions using R and Bioconductor. Springer, New York.

Smyth, G.K., J. Michaud, and H. Scott. 2005. The use of within-array replicate spots for assessing differential expression in microarray experiments. Bioinformatics 21:2067-2075.

Smyth, G.K. and T.P. Speed. 2003. Normalization of cDNA microarray data. Methods 31:265-273.

Steinbauer, C.E., G.P. Hoffman, and J.B. Edmond. 1943. Why are single plant yields of sweetpotato highly variable within plots? J. Amer. Soc. Hort. Sci. 43:249-254.

Takahata, Y., T. Noda, and T. Nagata. 1993. HPLC determination of $\beta$-carotene of sweetpotato cultivars and its relationship with color values. Jpn. J. Breeding 43:421-427.

Taylor, M. and G. Ramsay. 2005. Carotenoid biosynthesis in plant storage organs: recent advances and prospects for improving plant food quality. Physiol. Plant. 124:143-151.

Trethewey, R.N., P. Geigenberger, K. Riedel, M.R. Hajirezaei, U. Sonnewald, M. Stitt, J.W. Riesmeier, and L. Willmitzer. 1998. Combined expression of glucokinase and invertase in potato tubers leads to a dramatic reduction in starch accumulation and a stimulation of glycolysis. Plant J. 15:109-118.

van Jaarsveld, P.J., M.Faber, S.A. Tanumihardjo, P. Nestel, C.J.Lombard, and A.J.S. Spinnler-Benadé. 2005. $\beta$-Carotene-rich orange-fleshed sweetpotato improves the vitamin A status of primary school children assessed with the modified-relative-dose-response test. Amer. J. Clinical Nutr. 81:1080-1087.

Villordon, A.Q. and D.R. LaBonte. 1995. Variation in randomly amplified DNA markers and storage root yield in 'Jewel' sweetpotato clones. J. Amer. Soc. Hort. Sci. 120:734-740.

Villordon, A.Q. and D.R. LaBonte. 1996. Genetic variation among sweetpotatoes propagated through nodal and adventitious sprouts. J. Amer. Soc. Hort. Sci. 121:170-174.

Vishnevetsky, M., M. Ovadis, H. Itzhaki, M. Levy, Y. Libal-Weksler, Z. Adam, and A. Vainstein. 1996. Molecular cloning of a carotenoidassociated protein from Cucumis sativus corollas: Homologous genes involved in carotenoid sequestration in chromoplasts. Plant J. 10:1111-1118

Vishnevetsky, M., M. Ovadis, and A. Vainstein. 1999. Carotenoid sequestration in plants: The role of carotenoid-associated proteins. Trends Plant Sci. 4:232-235.

Whatley, J.M. and F.R. Whatley. 1987. When is a chromoplast? New Phytol. 106:667-678.

Yeum K.J. and R.M. Russell. 2002. Carotenoid bioavailability and bioconversion. Annu. Rev. Nutr. 22:483-504. 